straightened, antiseptic dressings were used and the long splint applied.

Eight days later there had been no rise in temperature since the operation. The splint was removed, fresh dressings applied, and the limb encased in plaster-of-Paris.

On Oct. 19th, assisted by Dr. Lyon, Mr. Renton operated on the left limb, treating it the same as the right, with the addition that the fibula was broken and the tendon of the biceps divided. Dressings and splints were used as before, and on Oct. 29 th plaster-of-Paris was applied.

Dec. 1st.-On removing the dressings the bones in both limbs were found perfectly firm, and the small wounds were healed.

28th.-Patient was able to walk, having gained two inches in height by the operation, and there being only four inches between the heels when the boy was lying comfortably on his back.

CASE 2. Double Talipes Equino-varus.-R. A-, aged six months, was admitted December 5th, 1878. On Dec. 7th, assisted by Dr. Beatson, Mr. Renton divided the tendo Achillis in each foot, and then, adopting the method of Dr. George Buchanan, he divided the whole of the structures in each sole subcutaneously, which immediately relieved all distorting causes. Two days after the operation Dr. Heron Watson's tin splints were applied posteriorly, and the case progressed favourably.

\section{THE BOROUGH HOSPITAL, BIRKENHEAD.}

FALL FROM A HEIGHT OF TWENTY FEET ; UNCONSCIOUSNESS LASTING NINETEEN DAYS; RECOVERY.

(Under the care of Dr. SPRATLY.)

For the following notes we are indebted to Mr. F. G. Baker, M.R.C.S., senior house surgeon.

W. T-, aged nine, was admitted into hospital on April 17th. The only history that could be got was that he was picked up at the bottom of a tower about twenty feet high, in the dock, in an unconscious state.

On admission, about 12.20 P.M., the patient was found to be perfectly unconscious; a large extravasation of blood completely closed the right eye, and extended about half way up the right side of the forehead, and slight bleeding from both nostrils. The right pupil was slightly more contracted and less active than the left, but was otherwise normal ; pulse and breathing were normal, as was the urine. There was no paralysis or discharge from the ear; no other injuries were found. Cold lotions were applied to the head, and a little milk was given by spoon. During the night he twice vomited blood. On the following day vomiting ceased. The patient then exhibited great irritability when the bruised eyelid was touched, turning away, and occasionally crying out, but he remained perfectly unconscious. Six grains of calomel were given, and shortly afterwards the bowels were opened.

On the 20th, a drachm of solution of perchloride of mercury and a grain and a half of iodide of potassinm were given in water three times a day; milk and beef-tea were frequently administered in small quantities. From this time up to May 6th the patient remained quite unconscious, but gradually became more and more restless, constantly trying to get out of bed and stand up, till it was with great difficulty he could be got to remain quiet for many minutes together. He took the milk and beef-tea, as also the medicine which was given, during the whole time. A seton was also applied to the nape of the neck. Liniment of iodine was painted on behind both ears. Up to this time not only was he perfectly insensible to all sound, but he did not recognise anyone. His eyes were usually open, and he was constantly looking about him and moving in bed.

On May 7 th he began to understand when spoken to loudly, and put out his tongue, \&c., when told; but he failed to recognise his mother and sister, though he looked at them when spoken to, neither did he speak.

On the 8th he asked for various things, and appeared more intelligent; he recognised members of his family, and talked rationally for a few minutes to his mother. The seton was removed, and liniment of iodine was repeated.

From this time up to May the 17 th he rapidly recovered, and on the 18th he appeared perfectly well, and went out every day afterwards. On the 23rd the pupils were quite normal, and with the exception of a slightly dazed look occasionally the patient appeared to be in his usual health.
The boy stated that at the time he met with the accident he was playing on some stairs in the tower, and fell over the balustrade, a distance of twenty feet, to the bottom.

\section{HEALTH OF LARGE ENGLISH TOWNS IN THE THIRTY-FIFTH WEEK OF 1879.}

JUDGED by the Registrar-General's mortality statistics, the public health continues in an unusually satisfactory condition. In twenty of the largest English towns, containing nearly a third of the entire population of England and Wales, 5176 births and 2731 deaths were registered last week. The births were 6 , and the deaths as many as 639 , below the average weekly numbers during 1878. The deaths, however, showed an increase of 171 upon the low number returned in the previous week. The annual rate of mortality fer 1000 persons living in these towns, which had been equal to 18.7 and 18.1 in the two preceding weeks, rose to $19 \cdot 3$ last week. During the past nine weeks of the past quarter ending the $30 \mathrm{th}$ ult., the death-rate in these towns averaged only $18 \cdot 0$ per 1000 , against $24.5,20.9$, and $25 \cdot 1$ in the corresponding periods of the three years 1876-7-8. The lowest death-rates in these towns last week were 11.1 in Portsmouth, 12.5 in Wolverhampton, 13.3 in Brighton, 13.7 in Bradford, and 14.5 in Oldham. The rates in the other towns ranged upwards to $20 \cdot 0$ in London, 21.6 in Liverpool, 21.8 in Plymouth, and 22.9 both in Manchester and in Leeds. The deaths referred to the seven principal zymotic diseases in the twenty towns further rose last week to 654 , of which 343 resulted from diarrhoea, and 109 from scarlet fever. The annual death-rate from these diseases averaged $4 \cdot 6$ per 1000 in the twenty towns, and ranged from 0.9 in Oldham to 5.7 in Liverpool. This zymotic rate was equal to $5 \cdot 6$ in London, while it did not average more than $3 \cdot 7$ in the nimeteen provincial towns; this excess of the zymotic death-rate in London was due to the greater fatality of diarrhca. Scarlet fever showed the greatest proportional fatality last week in Sunderland and Norwich ; enteric fever in Nottingham and Portsmouth. Diphtheria caused 13 deaths in London, and 8 in the provincial towns ; small-pox 7 in London, but not one in the nineteen other towns. The number of small-pox patients in the Metropolitan Asylum Hospitals declined during last week from 111 to $103 ; 20$ new cases were admitted to these hospitals last week, against 35 and 26 in the two previous weeks.

The fatal cases of diarrhoea in the twenty towns, which had risen from 86 to 258 in the four preceding weeks, further rose to 343 last week; in the corresponding weeks of the three years 1876-7-8 the recorded fatal cases were, however, 614,514 , and 512 respectively. Diarrhœa was proportionally most fatal last weel in Leicester, Liverpool, Leeds, and London. The annual death-rate from diarrhcea was equal to 3.0 per 1000 in London last week, whereas in the nineteen large provincial towns it did not average more than 1.9 .

\section{THE LATE MR. CLEMENT WILLIAMS.}

\section{To the Editor of THE LANCET.}

SIR, - With reference to that part of the letter of SurgeonMajor Robertson in your issue of the 22nd ultimo, in which he states that I asserted that Mr. Williams was the first European who visited Bhamo in recent times, I wish, with your permission, to say that, if he will again look over my short letter, he will find that I made no assertion, but simply alluded to the claims of Mr. Williams, which are, as he says, advanced in the preface of that gentleman's book.

Without wishing to lessen the credit due to Captain Hannay, Drs. Griffith and Bayfield, it will, I think, be generally admitted that if Mr. Williams was not the first to visit Bhamo, he was, at all events, the first whose journey was followed by useful results, as may be collected from one fact amongst many-viz., ihat from 1837 (the year of Bayfield's and Griffith's journey), when Colonel Burney, our political representative, withdrew in disgust from Ava, he was followed by no permanent successor till the advent of Williams, about a quarter of a century later.

I remain, Sir, your obedient servant,

D. H. CulumMore, F.R.C.S.E., \&c.

Tunbridge Wells, Sept. 1st, 1879. 